\title{
Coulisses
}

Revue de théâtre

25 | Hiver 2002

Varia

\section{Ida désœuvrée, une œuvre d'art plastique}

\section{Marion Schmitt}

\section{OpenEdition}

Journals

Édition électronique

URL : http://journals.openedition.org/coulisses/5958

DOI : $10.4000 /$ coulisses.5958

ISSN : 2546-9460

\section{Éditeur}

Presses universitaires de Franche-Comté

\section{Édition imprimée}

Date de publication : 1 janvier 2002

Pagination : 33

ISBN : 2-84627-052-X

ISSN : $1150-594 X$

\section{Référence électronique}

Marion Schmitt, «Ida désœuvrée, une œuvre d'art plastique », Coulisses [En ligne], 25 | Hiver 2002, mis en ligne le 24 octobre 2019, consulté le 15 novembre 2019. URL : http://journals.openedition.org/ coulisses/5958; DOI : 10.4000/coulisses.5958

Ce document a été généré automatiquement le 15 novembre 2019.

Coulisses 


\title{
Ida désœuvrée, une œuvre d'art plastique
}

\author{
Marion Schmitt
}

La comédienne joue la carte de la neutralité. Son rôle se veut celui d'une anticomédienne; ne rien faire paraître, refuser le jeu en quelque sorte pour laisser la place au " rien ", car ce n'est pas dans le texte que se trouve l'élément central de la pièce. En effet, sur une heure trente de représentation et les cent quarante pages du livre de Gertrude Stein, Patrick de Bergen ne retient qu'une dizaine de phrases en tout et pour tout. 
Ida

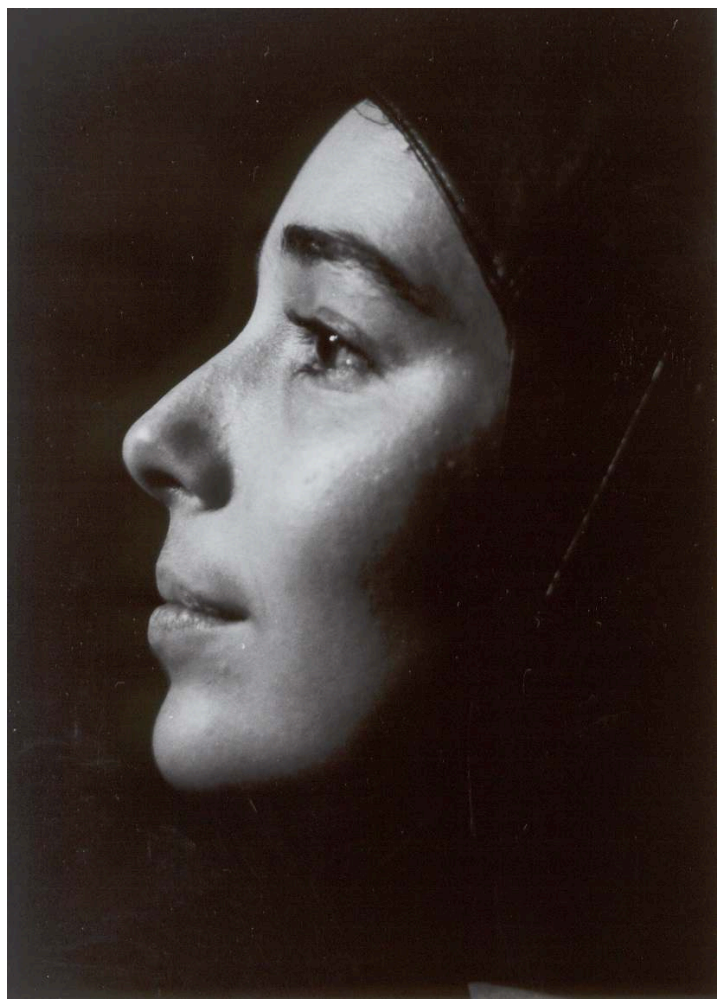

2 Si nous envisageons les différents composants de la pièce, nous remarquons que nous n'avons pas de texte, pas de véritable «jeu » d'acteur, mais alors où est le théâtre? C'est précisément là que l'on touche la forme toute particulière de Patrick de Bergen qui a essayé d'exploiter le « minimal » afin de retrouver le «vrai » théâtre. L'équipe d'Ida désœuvrée a voulu « calmer le jeu » pour mieux toucher le spectateur. Son théâtre se trouve à l'opposé du théâtre, qui devient cinéma, où l'on a de plus en plus d'images, de personnages, de costumes, de sons, de lumières. Cependant il prétend ne rien inventer, car il trouve son théâtre très proche du théâtre japonais qui joue également sur la lenteur.

3 Ce que j'ai vu était beau mais n'était pas du théâtre, au sens où je l'entends, on était plutôt face à une œuvre d'art plastique ou à un travail musical très précis. Savoir se fier aux minuscules incidents sensoriels qui peu à peu créent une disposition inédite à l'écoute et au regard, entendre des choses très fines qu'on ne soupçonne pas dans le bruit ordinaire (comme le clignement de cils pour le visuel). Il y a simplement à ressentir. Ida nous le dit elle-même, «Écoutez-moi il n'y a pas de réponse, vous voulez tous rentrer chez vous mais là-bas ce sera comme ici il n'y aura pas de réponse ». Et si l'on se demande où se trouve le point commun entre Gertrude Stein et Patrick de Bergen c'est que pour le metteur en scène tout comme pour l'écrivain « raconter ne les intéresse pas vraiment ». 


\section{AUTEUR}

\section{MARION SCHMITT}

Étudiante DEUG théâtre, $1^{\text {ère }}$ année 